\title{
Examining the influence of family physician supply on district health system performance in South Africa: An ecological analysis of key health indicators
}

\begin{tabular}{|c|c|}
\hline \multicolumn{2}{|c|}{$\begin{array}{l}\text { Authors: } \\
\text { Klaus B. von Pressentin }{ }^{1} \\
\text { Robert J. Mash } \\
\text { Tonya M. Esterhuizen }^{2}\end{array}$} \\
\hline \multicolumn{2}{|c|}{$\begin{array}{l}\text { Affiliations: } \\
\text { }{ }^{2} \text { Division of Family Medicine } \\
\text { and Primary Care, } \\
\text { Stellenbosch University, } \\
\text { South Africa }\end{array}$} \\
\hline \multicolumn{2}{|c|}{$\begin{array}{l}{ }^{2} \text { Biostatistics Unit, Faculty of } \\
\text { Medicine and Health } \\
\text { Sciences, Stellenbosch } \\
\text { University, South Africa }\end{array}$} \\
\hline \multicolumn{2}{|c|}{$\begin{array}{l}\text { Corresponding author: } \\
\text { Klaus von Pressentin, } \\
\text { kvonpressentin@sun.ac.za }\end{array}$} \\
\hline \multicolumn{2}{|c|}{$\begin{array}{l}\text { Received: } 05 \text { Sep. } 2016 \\
\text { Accepted: } 13 \text { Jan. } 2017 \\
\text { Published: } 28 \text { Apr. } 2017\end{array}$} \\
\hline \multicolumn{2}{|c|}{$\begin{array}{l}\text { How to cite this article: } \\
\text { Von Pressentin KB, Mash RJ, } \\
\text { Esterhuizen TM. Examining } \\
\text { the influence of family } \\
\text { physician supply on district } \\
\text { health system performance in } \\
\text { South Africa: An ecological } \\
\text { analysis of key health } \\
\text { indicators. Afr J Prm Health } \\
\text { Care Fam Med. 2017;9(1), } \\
\text { a1298. https://doi.org/ } \\
\text { 10.4102/phcfm.v9i1.1298 }\end{array}$} \\
\hline \multicolumn{2}{|c|}{$\begin{array}{l}\text { Copyright: } \\
\text { (c) 2017. The Authors. } \\
\text { Licensee: AOSIS. This } \\
\text { is licensed under the } \\
\text { Creative Commons } \\
\text { Attribution License. }\end{array}$} \\
\hline \multirow{2}{*}{ 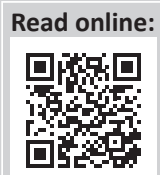 } & \\
\hline & $\begin{array}{l}\text { Scan this QR } \\
\text { code with your } \\
\text { smart phone or } \\
\text { mobile device } \\
\text { to read online. }\end{array}$ \\
\hline
\end{tabular}

Background: The supply of appropriate health workers is a key building block in the World Health Organization's model of effective health systems. Primary care teams are stronger if they contain doctors with postgraduate training in family medicine. The contribution of such family physicians to the performance of primary care systems has not been evaluated in the African context. Family physicians with postgraduate training entered the South African district health system (DHS) from 2011.

Aim: This study aimed to evaluate the impact of family physicians within the DHS of South Africa. The objectives were to evaluate the impact of an increase in family physician supply in each district (number per 10000 population) on key health indicators.

Setting: All 52 South African health districts were included as units of analysis.

Methods: An ecological study evaluated the correlations between the supply of family physicians and routinely collected data on district performance for two time periods: 2010/2011 and 2014/2015.

Results: Five years after the introduction of the new generation of family physicians, this study showed no demonstrable correlation between family physician supply and improved health indicators from the macro-perspective of the district.

Conclusion: The lack of a measurable impact at the level of the district is most likely because of the very low supply of family physicians in the public sector. Studies which evaluate impact closer to the family physician's circle of control may be better positioned to demonstrate a measurable impact in the short term.

\section{Introduction}

Strong primary health care systems require primary care teams that consist of an appropriate mix of health workers tailored to the health care needs of the communities they work in. ${ }^{1}$ The supply of appropriate health workers is a key building block in the World Health Organization's (WHO) model of effective health systems. ${ }^{2}$ In sub-Saharan African countries these primary care teams and their communities are challenged by a mix of health system constraints, socio-economic disparities and disease burdens. ${ }^{3}$ Primary care teams are stronger if they contain doctors with postgraduate training in family medicine. ${ }^{2}$ The contribution of such family physicians to the performance of primary care systems has been established in high-income countries. ${ }^{4,5}$ International studies (mainly in the USA, UK, Canada and Korea) described the public health benefits associated with an increased supply of primary care doctors, especially regarding a reduction in all-cause, infant and chronic disease-related morbidity and mortality. $6,7,8,9,10,11,12,13$ Many of these studies applied a broad definition of primary care doctors, by including all clinical specialities that work in primary care (family medicine, general practice, general internal medicine and general paediatrics).6,70,12,14 Some of these studies (notably UK and Canada) focused on family physicians or general practitioners, two terms which apply to the same professional: a primary care doctor with postgraduate training in family medicine or general practice. ${ }^{9,11,13}$

Family medicine is a young discipline in Africa, with a number of countries only commencing postgraduate training during the last decade. ${ }^{3,15,16,17,18,19,20,21,22}$ Qualitative studies have explored the opinions of African leaders and managers on the potential contribution and possible roles of family physicians in the district health system (DHS). ${ }^{23,24,25,26}$ There is, however, little quantitative evaluation of their actual impact to guide policy- and decision-makers on the deployment of family physicians. The uncertainty revolves around their cost-effectiveness and how best to 
position these family physicians within the different levels and components of the health system. The relationship between family physician supply and DHS performance has not been evaluated in the African context.

In South Africa, family medicine was gazetted as a new speciality during 2007 by the Health Professions Council of South Africa (HPCSA). 5,19 This event paved the way for structured postgraduate training through training posts (registrars) and a consensus on training outcomes. ${ }^{5}$ This developmental phase included the creation of new family physician posts within the DHS. These posts are mainly at district hospitals and community health centres, although a few are located at regional hospitals. During this same period, the National Department of Health (NDoH) started implementing primary health care reforms, which included family physicians within district clinical specialist teams that were tasked with strengthening maternal and child health care..$^{27,28,29}$ In addition, the new national policy on human resources for health and the national development plan support the deployment of family physicians within the DHS, but lack sufficient detail to guide managers on how best to utilise these expert generalists. ${ }^{30}$ Following further discussions with the national department, a national position paper was published by the leadership of academic family medicine, in order to clarify the contribution of family physicians to the DHS. ${ }^{5}$ This consensus statement introduced the 'new' definition of the family physician as an expert generalist in the DHS capable of supporting and leading health care teams through six interwoven roles: competent clinician, consultant to the primary care team, capacity builder, leader of clinical governance, supporter of community-orientated primary care and in some instances a supervisor of under- or postgraduate students.

The first graduates of the new training programmes entered the DHS from 2011. ${ }^{5}$ Family physicians from the previous training programmes in South Africa and elsewhere still form the bulk of the available family physicians, as the nine South African training institutions are not yet training to the scale envisaged by the national position paper. ${ }^{5}$ The training standards are coordinated through the South African Academy of Family Physicians (SAAFP), and the South African College of Family Physicians (CFP) is responsible for the national exit examination. The nine training institutions, SAAFP and CFP successfully responded to a funding call from the $\mathrm{NDoH}$ and EuropeAid to implement a project aimed at strengthening the contribution of family physicians to the primary health care system. ${ }^{31}$ This project included an applied research activity, which aimed to evaluate the initial impact of family physicians on the DHS in South Africa. This article presents one of the four complementary studies and looks at the relationship between the supply of family physicians and DHS performance. The other three studies consist of a quasiexperimental comparison of facilities with and without family physicians, a 360-degree evaluation of family physician's impact by their colleagues and qualitative interviews with district managers who employ family physicians.

\section{Aim and objectives}

This study aimed to evaluate the impact of family physicians within the DHS of South Africa. The objectives were to evaluate the impact of an increase in family physician supply in each district (number per 10000 population) on key health system performance indicators, key clinical processes and key health outcomes.

\section{Research methods and design \\ Study design}

This ecological study was informed by a pilot study conducted in the Western Cape, South Africa. ${ }^{32}$ A retrospective cohort design was used, whereby data were collected for the period 2010/2011 as a baseline and 2014/2015 representing 5 years post-deployment of the new generation of family physicians. The STROBE statement's checklist for reporting cohort studies was used as standard for presenting this research. $^{33}$

\section{Setting}

This study evaluated all 52 health districts across all nine provinces of South Africa (a national study frame, see Figure 1) for two time periods.

\section{Study population and sampling strategy}

All 52 South African health districts were included as units of analysis.

\section{Data collection}

A national dataset, the District Health Barometer (DHB), contributed the data on district performance for two time periods: 2010/2011 and 2014/2015. ${ }^{35,36}$ The DHB draws data from several data sources provided by the $\mathrm{NDoH}$. Compilation of the DHB is guided by an advisory committee

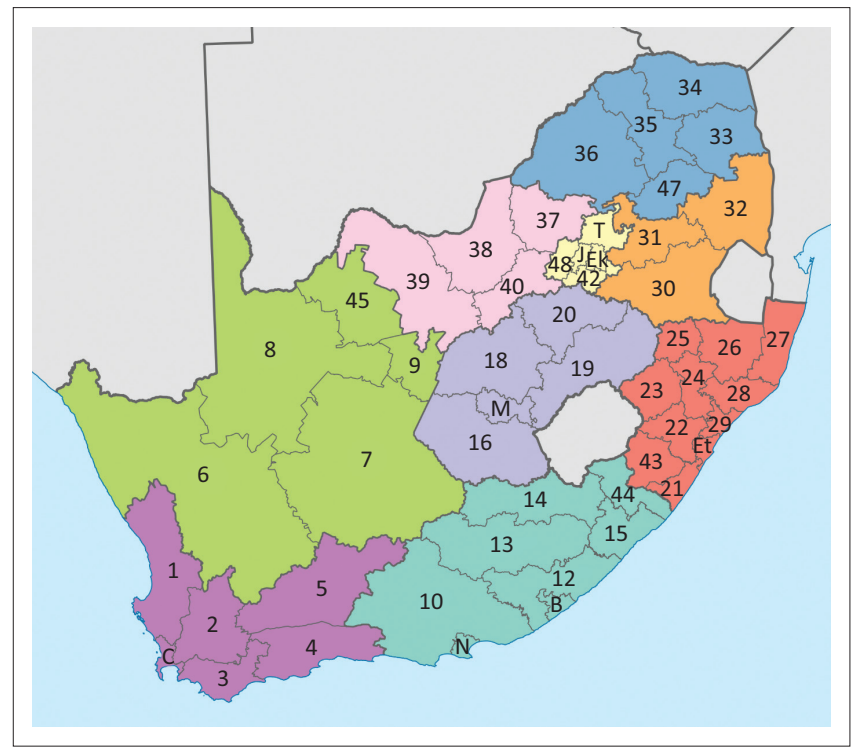

Source: Districts of South Africa. ${ }^{34}$

FIGURE 1: Map of South Africa depicting its 52 districts. 
made up of managers from the NDoH, as well as health experts from Health Systems Trust (HST). The DHB is designed to assist the $\mathrm{NDoH}$ in monitoring health service delivery at district level for all of South Africa's health districts. Furthermore, the HST encourages providers, managers, researchers and policy-makers to use DHB information by making the publication and its data freely available online on their website.

Table 1 presents the list of DHB indicators used. The DHB system of categorising the indicators was used throughout (ranging from financial indicators to clinical process and outcome indicators). The official DHB indicator descriptions are also presented in Table 1.

For the family physician supply, public sector family physicians working in joint appointments (with the universities) or nonjoint appointments and employed at facility-, sub-district and district levels (including district office and district clinical specialist team appointments) were included. Those family physicians employed at regional or tertiary hospitals in fulltime academic positions or in the private sector were excluded. The data on family physician supply per district for these two time periods were obtained from all nine academic institutions involved with postgraduate family medicine training in South Africa and who were familiar with the health system in their catchment area. The absolute numbers of family physicians were converted to family physician supply per 10000 population (using the DHB population data for the respective time periods).

\section{Data analysis}

The DHB data, as well as data on family physician supply, were entered into an Excel sheet and subsequently converted into IBM SPSS version 23 for descriptive and inferential analyses. ${ }^{37}$

The data analysis included all 52 units of analysis and commenced with descriptive analysis of the independent and dependent variables. Subsequently, the correlation between change in family physician supply and change in the indicators available for both time periods (37 indicators) was analysed. In addition, a cross-sectional correlation analysis was performed for time period $2(2014 / 2015)$ on the remaining DHB data set (data for 12 indicators were available only for time period 2). Simple scatterplots of the bivariate correlations were inspected to identify the nature of each relationship. A non-parametric test, Spearman's rho, was selected to test for correlation between the independent and dependent variables, because of the non-parametric distribution of the data as well as the presence of outliers (especially in reference to the independent variable). The level of significance chosen was $p<0.05$. For those relationships found to be linear and showing at least a lowto-moderate correlation coefficient (see interpretation guide below), further regression analysis was performed using a generalised linear model (GLM), to control for the effect of available confounders, namely province and socio-economic quintile (SEQ) of the districts. Using GLMs with province as covariate created better regression models as opposed to GLMs with SEQ as covariate (using the omnibus test and its likelihood ratio Chi-square value as guide).

Correlation values may be interpreted as: $:^{32,38}$

$0.90-1.00(-0.9$ to -1.00$) \quad$ Very high positive (negative) correlation

$0.70-0.90(-0.70$ to -0.90$) \quad$ High positive (negative) correlation

$0.50-0.70(-0.50$ to -0.70$) \quad$ Moderate positive (negative) correlation

$0.30-0.50(-0.30$ to -0.50$) \quad$ Low positive (negative) correlation

0.00-0.30 (0.00 to -0.30$) \quad$ Negligible correlation

\section{Ethical considerations}

This study was approved by the Health Research Ethics Committee, Stellenbosch University (reference S15/01/003) and HST also confirmed their permission for use of the open access data.

\section{Results}

Tables 2 and 3 present descriptive statistics for the dependent variables, as well as the results for the non-parametric correlation analysis. The median (and interquartile range) of the independent variable, the supply of family physician per 10000 total population, was $0.027(0.000-0.043)$ for time period 1 and $0.035(0.016-0.054)$ for time period 2 . The medians (and interquartile ranges) for the absolute numbers of family physicians per district were $2.00(0.00-4.00)$ for time period 1 and 2.00 (1.00-5.00) for time 2 (total numbers were 153.5 for time period 1 and 208.5 for time period 2). The majority of correlations were negligible to low and not statistically significant. Two correlations from the change over time correlation analysis were found to be statistically significant (using the initial Spearman's rho analysis): a HIV management indicator, 'Percentage of TB cases with known HIV status' (low negative correlation, rho $=-0.351, p=0.011$ ) and an additional indicator, 'Vaccine expenditure per population under 1 year', a measure of the efficiency of immunisation and not the coverage (low negative correlation, rho $=-0.378, p=0.006$ ). One indicator from the cross-sectional time 2 analysis showed a statistically significant, low negative correlation, namely 'Inpatient crude death rate' (rho $=-0.340, p=0.014$ ). Scatter plots of these correlations are shown in Figures 2, Figure 3 and Figure 4. The influence of the three outlying values was clear on inspection: for example, the scatterplot of 'Percentage of TB cases with known HIV status' (Figure 2) showed a random scatter if one ignores the three outliers.

Regression analysis of these three correlations was performed. After adjusting for province in a GLM, the overall vaccine expenditure became positive in most of the nine provinces (see Table 4). This is a real example of confounding by province. Relative to the Western Cape Province, most of the provinces increased their expenditure on vaccines between time periods 1 and 2 . The effect of 
TABLE 1: List of DHB data indicators arranged by DHB categories..$^{35}$

\begin{tabular}{ll}
\hline Category & DHB indicator name \\
\hline Finance & $\begin{array}{l}\text { Provincial and LG PHC expenditure per } \\
\text { PHC headcount }\end{array}$ \\
& $\begin{array}{l}\text { Provincial and LG expenditure on } \\
\text { District Health Services per capita } \\
\text { (uninsured) }\end{array}$ \\
& $\begin{array}{l}\text { Provincial and LG PHC expenditure per } \\
\text { capita (uninsured) }\end{array}$ \\
& $\begin{array}{l}\text { Provincial and LG expenditure on } \\
\text { District Health Services per capita (tota } \\
\text { population) }\end{array}$ \\
& $\begin{array}{l}\text { Provincial and LG PHC expenditure per } \\
\text { capita (total population) }\end{array}$ \\
& PHC supervisor visit rate (fixed clinic/ \\
& CHC/CDC)
\end{tabular}
DHB 2014/2015 description of the indicators

Provincial and LG expenditure under programme 2 (budget for District Health Services) per PHC headcount on non-hospital PHC divided by the total PHC headcount. PHC programmes include nutrition; HIV and AIDS; community-based services; community health centres; and community health clinics.

Provincial and LG expenditure per capita (uninsured) on DHS is the total amount spent per person without medical aid coverage. The numerator is the sum of provincial and LG expenditure under programme 2, except for expenditure on sub-programme 2.8 (Coroner Services). The denominator is the estimated uninsured population per district. Uninsured sub-programme 2.8 (Coroner Services). The dene
individuals have no medical scheme coverage.

PHC expenditure for the uninsured population includes expenditure on sub-programmes 2.2-2.7 of the DHS expenditure. This forms the numerator for this indicator. The denominator is the estimated uninsured population per area. on DHS (all sub-programmes except 2.8 Coroner services) per person with and without medical scheme coverage. population) $\begin{aligned} & \text { Provincial and LG PHC expenditure per } \\ & \text { capita (total population) }\end{aligned}$
a percentage of the total population in the district.

$\mathrm{PHC} \quad \mathrm{CHC} / \mathrm{CDC}$

\section{Management ALOS (district hospitals)}

Inpatients

npatient

mortality

Child under 5 years diarrhoea case fatality rate

Child under 5 years pneumonia case fatality rate

Child under 5 years severe acute malnutrition case fatality rate ${ }^{a}$ ICDR

Delivery care Delivery in facility under 18 years rate

Inpatient ENDR ${ }^{a}$

Maternal mortality in facility ratio ${ }^{a}$

Stillbirth in facility rate ${ }^{a}$

Delivery by C-section rate (district hospitals) ${ }^{\mathrm{a}}$

Mother postnatal visit within 6 days rate $^{\mathrm{a}}$

PMTCT

Antenatal first visit before 20 weeks rate $^{\mathrm{a}}$

Antenatal client initiated on ART rate

Infant first PCR test positive around 6 weeks rate ${ }^{a}$

Infant first PCR test around 6 weeks uptake rate ${ }^{\mathrm{a}}$

(annualised)
The PHC facility supervision rate is the number of fixed PHC facilities, including CHCs and CDCs, visited by a clinica supervisor at least once a month, as a proportion of the total number of fixed PHC facilities. A dedicated clinic supervisor conducts the visit according to the clinic supervision manual, which entails use of the red flag and/or regular review tools. Each fixed facility should be visited by a clinic supervisor once a month.

ALOS refers to the average number of days that patients spend in hospital. It is generally calculated as follows: total number of inpatient days during a year plus half the number of day patients, divided by the number of separations (deaths, discharges and transfers out).

BUR measures the occupancy of available beds and therefore indicates how efficiently a hospital is using its available capacity. It is calculated as follows: the number of inpatient days is added to half the number of day patients, and divided by the usable bed days; this is expressed as a percentage.

OPD new client not referred rate refers to the percentage of new outpatient clients who enter a hospital without a referral letter. The percentage is calculated by dividing new OPD cases that are not referred (numerator) by all new OPD cases (denominator). OPD follow-up and emergency clients are excluded from the denominator. OPD new client not referred rate monitors the utilisation trends of clients who by-pass PHC facilities.

a Expenditure per PDE is a composite process indicator that connects financial data with service-related data from the hospital admissions and outpatients' records. This indicator measures how the resources available to the hospital are being spent and is a marker of efficiency. The indicator measures the average cost per PDE at a district hospital and is expressed as Rand per PDE. The indicator value is calculated by dividing the total expenditure of the hospital (within budget programme 2: district health services, as recorded in the BAS) by the number of PDEs. PDEs are calculated by adding the number of inpatients, plus half of day patients, plus one-third of outpatients and emergency room visits, as recorded in the DHIS. As expenditure per PDE is a ratio between costs and services, improved performance is possible if costs are reduced or utilisation increased.

CFRs for diarrhoea, pneumonia and SAM in children under 5 years of age. The CFR for the priority childhood illnesses (pneumonia, diarrhoea and SAM) is the proportion of all children under 5 years admitted to hospital with these conditions that die during the admission.

The ICDR is an impact indicator that refers to the proportion of all inpatient separations because of death. Inpatient separations include inpatient transfers out, deaths and inpatient discharges. The indicator therefore includes deaths from all causes that occur in a health facility.

This indicator measures the proportion of all deliveries that occur among women younger than 18 years. The numerator is the number of deliveries among women under 18 years of age, while the denominator represents all deliveries that have been recorded at the health facility. This outcome indicator is used as a proxy to track success in the prevention of teenage pregnancies.

The inpatient ENDR or inpatient death 0-7 days measures the number of deaths among live born babies that occur within seven completed days after birth per 1000 live births. It only includes neonatal deaths when the foetus is at 26 or more weeks' gestational age and/or weighs $500 \mathrm{~g}$ or more.

The WHO definition of a maternal death is the death of a woman while pregnant or within 42 days of termination of pregnancy, irrespective of the duration and site of the pregnancy, from any cause related to or aggravated by the pregnancy, irrespective of the duration and site of the pregnancy, from any cause related to or aggravated by the
pregnancy or its management, but not from accidental or incidental causes. The MMR is the number of maternal deaths pregnancy or its management, but not from accidental or incidental causes. The MMR is the number of
per 100000 live births. This indicator refers to the facility-based (and not the population-based) MMR.

The stillbirth rate measures the number of babies born dead per 1000 total births. The indicator does not differentiate between fresh and macerated stillbirths. Stillbirths should only be counted when the foetus is at 26 or more weeks of gestational age and/or weighs $500 \mathrm{~g}$ or more.

The $\mathrm{C}$-section rate measures the proportion of deliveries in hospitals that are carried out by C-section. The numerator is the number of C-sections conducted in the facility, and the denominator is the number of deliveries that took place in that facility over the same time period. It is therefore a facility-based and not a population-based indicator. This chapter focuse on $\mathrm{C}$-sections performed at district hospitals.

The mother postnatal visit within 6 days rate indicator monitors access to postnatal care. The numerator for this indicator is the number of postnatal visits by a mother within 6 days of delivery, either at a PHC facility or a postnatal home visit by facility staff. The purpose of the visit is for a postnatal check-up. Only the first visit after delivery should be counted. The denominator is the number of deliveries in facility. Deliveries include deliveries at hospitals and at PHC facilities.

Early registration for antenatal care is an important entry point into the health system for pregnant women, allowing them to access health care services (and health information), including PMTCT services. This indicator shows the percentage of pregnant women who have their first antenatal visit before 20 weeks, out of all antenatal clients' first visits (those whose first visit was before and after 20 weeks).

All HIV-positive pregnant women should be initiated on ART at the first antenatal visit if not already on ART. The antenatal client initiated on ART rate indicator measures the percentage of antenatal clients initiated on ART out of all antenatal clients eligible for ART.

This indicator measures the percentage of HIV-exposed infants who receive an early HIV test (around 6 weeks of age). It is calculated by dividing the number of PCR tests performed in infants around 6 weeks (numerator) by live births to HIV-positive women (denominator). It can be used as a proxy for early infant diagnosis coverage.

This indicator measures the percentage of early infant PCR tests that have a positive result; it is used as a proxy for early vertical (intra-uterine and intra-partum) transmission for those infants who access an early PCR test.

Child Health Vitamin A dose 12-59 months coverage Proportion of children 12-59 months who received vitamin A 200000 units, preferably every 6 months. 
TABLE 1 (Continues...): List of DHB data indicators arranged by DHB categories. ${ }^{35}$

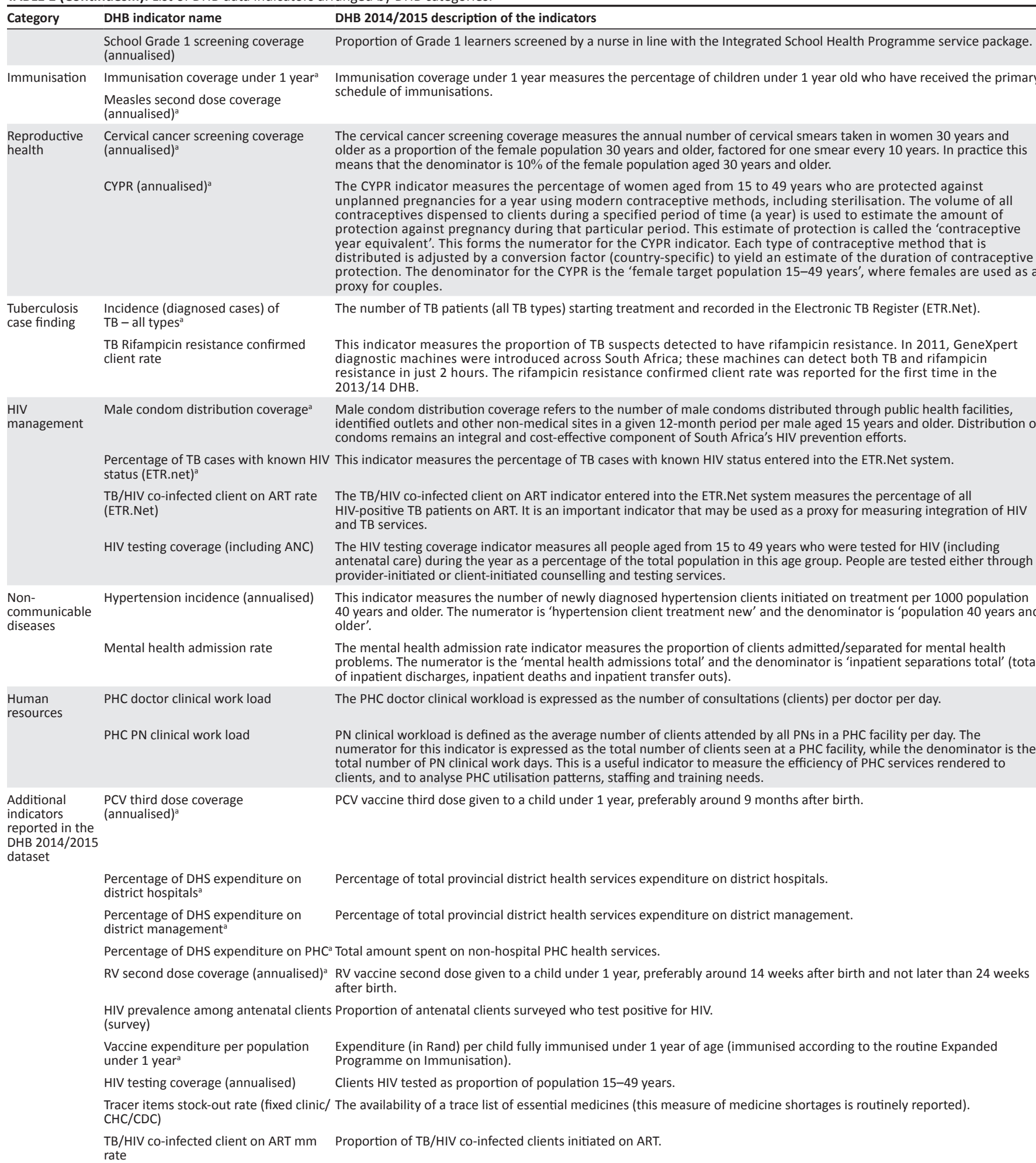

Source: The definitions of the indicators were adopted from Massyn $\mathrm{n}^{35}$

andicators available for both time periods.

ALOS, average length of stay; ANC, antenatal care; ART, antiretroviral therapy; BAS, Basic Accounting System; BUR, bed utilisation rate; CFRs, case fatality rates; CHC, community health centre; CDC, community day centre; C-section, caesarean section; CYPR, couple year protection rate; DHIS, District Health Information Software; DHB, District Health Barometer; DHS, District Health System; ENDR, early neonatal death rate; ETR.Net, Electronic TB Register; ICDR, inpatient crude death rate; LG, local government; MMR, maternal mortality ratio; OPD, outpatient department; PCR, polymerase chain reaction; PCV, pneumococcal vaccine; PDE, patient day equivalent; PHC, primary health care; PMTCT, prevention of mother-to-child transmission; PN, professional nurse; RV, Rota virus; SAM, severe acute malnutrition; TB, tuberculosis; WHO, World Health Organization.

family physicians (not statistically significant at $p=0.861$ ) only accounted for an additional R268.249 (after subtracting the intercept value R107.949 from the B coefficient, R376.198). A similar influence of province on the correlation between family physician supply for time period 2 and 'Inpatient crude death rate' was demonstrated in a different GLM (Table 5). The correlation remained negative, but decreased in its strength and became non-significant 
TABLE 2: Correlations: difference over time (37 variables available for both time periods).

\begin{tabular}{|c|c|c|c|c|}
\hline DHB indicator name (unit) & $\begin{array}{l}\text { 2010/2011 } \\
\text { Median (IQR) }\end{array}$ & $\begin{array}{l}\text { 2014/2015 } \\
\text { Median (IQR) }\end{array}$ & Spearman's rho & $p$ \\
\hline \multicolumn{5}{|l|}{ Financial indicators } \\
\hline Provincial and LG PHC expenditure per PHC headcount (Rand) & $262.78(232.49-291.32)$ & $314.15(276.35-342.80)$ & 0.192 & 0.174 \\
\hline $\begin{array}{l}\text { Provincial and LG expenditure on District Health Services per capita } \\
\text { (uninsured) (Rand) }\end{array}$ & $1430.15(1232.31-1571.91)$ & $1600.22(1351.84-1895.19)$ & 0.015 & 0.917 \\
\hline Provincial and LG PHC expenditure per capita (uninsured) (Rand) & 761.89 (672.41-828.93) & $929.56(794.46-1018.46)$ & 0.136 & 0.336 \\
\hline $\begin{array}{l}\text { Provincial and LG expenditure on District Health Services per capita } \\
\text { (total pop) (Rand) }\end{array}$ & $1218.82(1028.83-1462.29)$ & $1341.33(1149.76-1737.68)$ & 0.012 & 0.933 \\
\hline Provincial and LG PHC expenditure per capita (total pop) (Rand) & $629.89(577.72-713.14)$ & $755.34(674.76-898.70)$ & 0.132 & 0.351 \\
\hline \multicolumn{5}{|l|}{ Management of PHC } \\
\hline PHC supervisor visit rate (fixed clinic/CHC/CDC) (\%) & $66.50(54.09-83.73)$ & $77.53(62.15-85.22)$ & 0.125 & 0.376 \\
\hline \multicolumn{5}{|l|}{ Management of inpatients } \\
\hline Average length of stay (district hospitals) (days) & $4.02(3.04-5.22)$ & $4.32(3.51-5.37)$ & -0.205 & 0.145 \\
\hline Inpatient bed utilisation rate (district hospitals) (\%) & $64.42(60.57-71.62)$ & $66.70(59.33-73.18)$ & -0.83 & 0.557 \\
\hline OPD new client not referred rate (district hospitals) (\%) & $63.98(35.39-82.41)$ & $59.87(42.94-70.15)$ & -0.148 & 0.337 \\
\hline \multicolumn{5}{|l|}{ Inpatient mortality } \\
\hline Child under 5 years diarrhoea case fatality rate (\%) & $7.81(3.19-10.05)$ & $2.97(1.79-4.68)$ & 0.73 & 0.608 \\
\hline Child under 5 years pneumonia case fatality rate $(\%)$ & $6.22(3.09-9.03)$ & $2.66(1.61-4.45)$ & -0.085 & 0.548 \\
\hline Child under 5 years severe acute malnutrition case fatality rate $(\%)$ & $17.46(10.76-23.12)$ & $11.14(8.27-15.04)$ & 0.005 & 0.975 \\
\hline \multicolumn{5}{|l|}{ Delivery care } \\
\hline Delivery in facility under 18 years rate $(\%)$ & $8.58(7.25-10.22)$ & $8.00(6.97-9.81)$ & 0.098 & 0.49 \\
\hline Inpatient early neonatal death rate (per 1000 live births) & $9.64(8.26-13.04)$ & $10.27(8.34-12.40)$ & 0.14 & 0.321 \\
\hline Maternal mortality in facility ratio (per 100000 live births) & $132.51(58.38-197.22)$ & $130.21(69.80-195.03)$ & 0.036 & 0.802 \\
\hline Stillbirth in facility rate (\%) & $22.95(18.87-25.98)$ & $20.88(16.99-24.15)$ & -0.143 & 0.312 \\
\hline Delivery by caesarean section rate (district hospitals) (\%) & $18.43(13.13-22.20)$ & $21.86(18.94-27.33)$ & -0.19 & 0.177 \\
\hline Mother postnatal visit within 6 days rate $(\%)$ & $29.28(11.84-44.09)$ & $69.31(56.48-76.00)$ & 0.056 & 0.695 \\
\hline \multicolumn{5}{|l|}{ РMTCT } \\
\hline Antenatal first visit before 20 weeks rate $(\%)$ & $40.38(34.98-45.55)$ & $56.95(52.54-60.89)$ & -0.148 & 0.295 \\
\hline Antenatal client initiated on ART rate (\%) & $74.63(52.08-109.10)$ & $92.21(87.41-95.98)$ & 0.052 & 0.716 \\
\hline \multicolumn{5}{|l|}{ Child health immunisation } \\
\hline $\begin{array}{l}\text { Vitamin A dose } 12-59 \text { months coverage (annualised) (proportion of } \\
\text { children aged } 12-59 \text { months) }\end{array}$ & $32.98(26.00-38.14)$ & $51.01(46.56-58.25)$ & 0.086 & 0.544 \\
\hline Immunisation coverage under 1 year ( $\%)$ & $77.35(70.11-88.55)$ & $82.88(78.77-92.92)$ & -0.107 & 0.452 \\
\hline Measles second dose coverage (annualised) (\%) & $78.96(72.62-85.94)$ & $79.28(73.59-87.72)$ & 0.134 & 0.343 \\
\hline \multicolumn{5}{|l|}{ Reproductive health } \\
\hline $\begin{array}{l}\text { Cervical cancer screening coverage (annualised) (proportion of the } \\
\text { female population 15-44 years) }\end{array}$ & $49.20(39.36-61.74)$ & $54.73(41.68-66.30)$ & -0.146 & 0.3 \\
\hline $\begin{array}{l}\text { Couple year protection rate (annualised) (proportion of the female } \\
\text { population } 30 \text { years and older) }\end{array}$ & $28.98(25.56-36.39)$ & $45.92(39.61-52.37)$ & 0.026 & 0.854 \\
\hline \multicolumn{5}{|l|}{ TB case finding } \\
\hline $\begin{array}{l}\text { Incidence (diagnosed cases) of TB - all types (per } 100000 \text { people } \\
\text { in the catchment population) }\end{array}$ & $919.30(653.34-1063.57)$ & $680.27(504.10-831.39)$ & 0.019 & 0.893 \\
\hline \multicolumn{5}{|l|}{ HIV management } \\
\hline Male condom distribution coverage (number of male condoms) & $12.28(8.93-16.04)$ & $36.78(24.49-46.53)$ & 0.087 & 0.542 \\
\hline Percentage of TB cases with known HIV status (ETR.net) (\%) & $73.11(68.25-79.52)$ & $93.07(90.73-94.93)$ & -0.351 & $0.011 *$ \\
\hline \multicolumn{5}{|l|}{ Additional indicators } \\
\hline PCV third dose coverage (annualised) (\%) & $74.95(63.06-82.80)$ & $86.09(81.20-96.20)$ & 0.047 & 0.74 \\
\hline Percentage of DHS expenditure on district hospitals (\%) & $44.23(33.75-49.42)$ & $37.99(27.58-48.16)$ & -0.038 & 0.791 \\
\hline Percentage of DHS expenditure on district management (\%) & $5.57(2.90-6.89)$ & $5.49(3.24-8.06)$ & 0.094 & 0.507 \\
\hline Percentage of DHS expenditure on PHC (\%) & $53.88(45.80-61.08)$ & $58.00(48.21-66.74)$ & 0.006 & 0.968 \\
\hline RV second dose coverage (annualised) (\%) & $72.57(61.76-82.77)$ & $89.32(82.89-100.08)$ & 0.072 & 0.612 \\
\hline Vaccine expenditure per population under 1 year (Rand) & $925.74(0.35-1278.64)$ & $1282.37(902.57-1445.37)$ & -0.378 & $0.006^{*}$ \\
\hline
\end{tabular}

*, Statistically significant at $p<0.05$.

IOR, interquartile range; LG, local government; DHB, District Health Barometer; PMTCT, prevention of mother-to-child transmission; PCR, polymerase chain reaction; DHS, District Health System PCV, pneumococcal vaccine; RV, Rota virus; ETR.Net, Electronic TB Register; PHC, primary health care; CHC, community health centre; CDC, community day centre; OPD, outpatient department; LG, local government.

(B coefficient for family physician supply in time period 2 was -0.024 with $p=0.334$; intercept B coefficient $=3.250$ ). The influence of province on the correlation between family physician supply over time and 'Percentage of TB cases with known HIV status', however, was not demonstrated in a GLM (Table 6). Here the B coefficient for change in family physician supply was $-138.039 \%$ with $p=0.029$; intercept B coefficient $=15.143 \%$. The overall 
TABLE 3: Cross-sectional correlations time period 2 (12 additional variables only available for time period 2).

\begin{tabular}{|c|c|c|c|}
\hline DHB indicator name (unit) & 2014/2015 Median (IQR) & Spearman's rho & $\bar{p}$ \\
\hline \multicolumn{4}{|l|}{ Inpatient mortality } \\
\hline Inpatient crude death rate (proportion of all inpatient separations) & $5.54(4.66-6.36)$ & -0.34 & $0.014 *$ \\
\hline \multicolumn{4}{|l|}{ Child health immunisation } \\
\hline School Grade 1 screening coverage (annualised) (\%) & $21.37(13.31-32.69)$ & 0.23 & 0.102 \\
\hline \multicolumn{4}{|l|}{ TB case finding } \\
\hline TB rifampicin resistance confirmed client rate ( $\%$ of positive TB tests that are rifampicin resistant) & $5.95(4.76-7.04)$ & -0.052 & 0.712 \\
\hline \multicolumn{4}{|l|}{ HIV care } \\
\hline TB/HIV co-infected client on ART rate (ETR.Net) (\%) & $81.32(70.21-86.83)$ & -0.261 & 0.061 \\
\hline HIV testing coverage (including ANC) (\%) & $32.84(27.04-41.33)$ & 0.012 & 0.931 \\
\hline \multicolumn{4}{|l|}{ NCD care } \\
\hline Hypertension incidence (annualised) (per 1000 population 40 years and older) & $14.82(11.82-17.69)$ & -0.18 & 0.201 \\
\hline Mental health admission rate (proportion of clients admitted/separated for mental health problems) & $0.96(0.53-1.72)$ & -0.066 & 0.641 \\
\hline \multicolumn{4}{|l|}{ Human resources } \\
\hline PHC doctor clinical work load (average number of clients seen per doctor per clinical work day) & $25.46(19.05-32.87)$ & 0.073 & 0.608 \\
\hline \multicolumn{4}{|l|}{ Additional indicators } \\
\hline HIV testing coverage (annualised) (\%) & $29.39(24.39-37.22)$ & 0.036 & 0.799 \\
\hline Tracer items stock-out rate (fixed clinic/CHC/CDC) (\%) & $16.35(8.26-32.69)$ & -0.131 & 0.353 \\
\hline TB/HIV co-infected client on ART rate (\%) & $48.44(35.37-59.34)$ & 0.221 & 0.14 \\
\hline
\end{tabular}

*, Statistically significant at $p<0.05$.

IQR, interquartile range; DHB, District Health Barometer; TB, tuberculosis; ANC, antenatal care; ART, antiretroviral therapy; ETR.Net, Electronic TB Register; PHC, primary health care; CHC, community health centre; CDC, community day centre; NCD, Non-Communicable Disease.

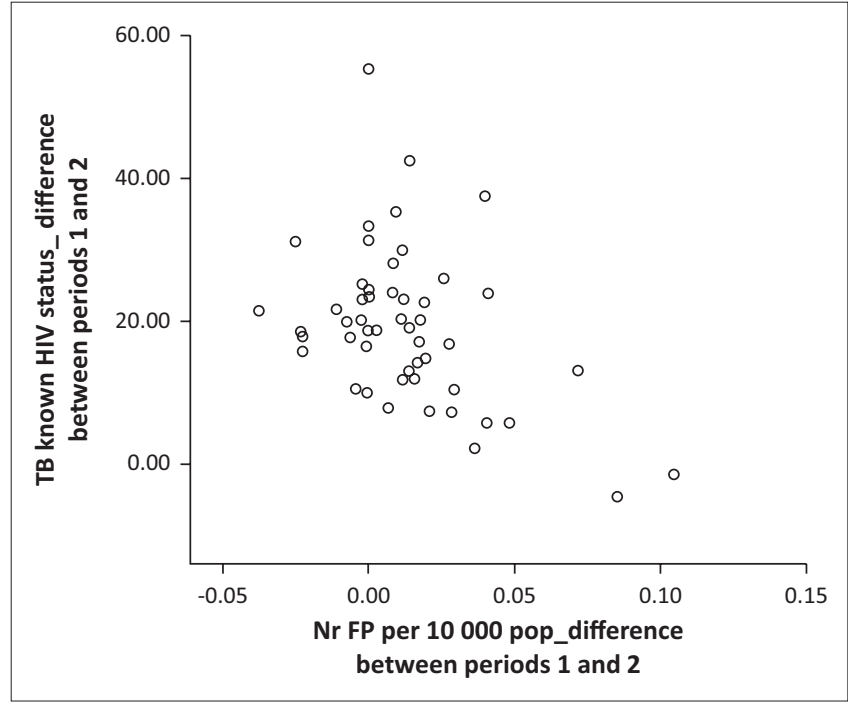

FIGURE 2: Scatter plot of significant correlation $(p<0.05)$ : difference between time periods 1 and 2 for supply of family physicians (FPs) and percentage of TB cases with known HIV status.

significance of the provincial covariate was $p=0.810$ (Wald Chi-Square test).

\section{Discussion}

\section{Key findings}

Five years after the introduction of family physicians this study showed no demonstrable correlation between family physician supply and improved health indicators from the macro-perspective of the district. The lack of a measurable impact at the level of the district is most likely because of the very low supply and deployment of family physicians in the public sector, which makes their impact undetectable.

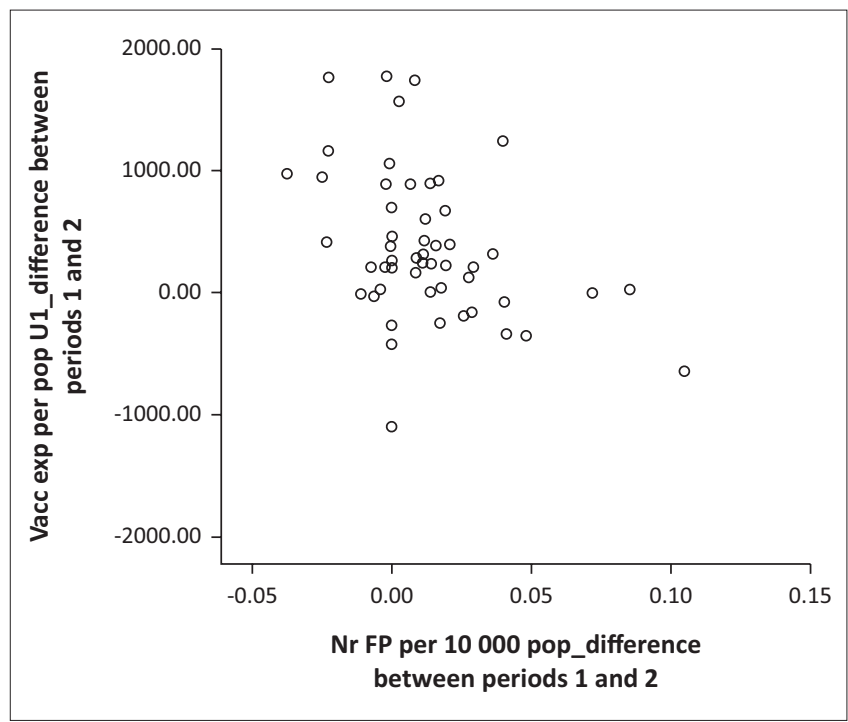

FIGURE 3: Scatter plot of significant correlation $(p<0.05)$ : difference between time periods 1 and 2 for supply of family physicians (FPs) and vaccine expenditure per population under 1 year.

\section{Discussion of key findings}

The family physician supply in the international literature (supply ranging between 4.3 and 12.0 per 10000 population in countries such as the USA, UK, Canada and Korea) was at least 100 times more than the 0.03 per 10000 reported here. Our definition of family physician supply, however, differed from the definitions of primary care physician supply in these references, as the international literature generally included all clinical primary care physicians (usually with postgraduate training in specialities such as paediatrics and internal medicine). These international studies were also conducted in less socio-economically deprived settings 
where postgraduate training of primary care physicians was well established. It may be more appropriate to compare our family physician supply to that of other BRICS countries (Brazil, Russia, India, China and South Africa): the total family physician supply in South Africa (private and public sector, all levels of health care) was 0.1 per 10000 in 2015, compared to 0.2 per 10000 in Brazil and 1.2 per 10000 in China. ${ }^{39}$ The total South African supply of family physician per 10000 needs to double in order to meet at least Brazil's supply. South Africa's $\mathrm{NDoH}$ echoes this by identifying a shortfall of 888 family physicians in their $2011 \mathrm{HR}$ policy document. ${ }^{30}$

While some correlations demonstrate a possible trend, the size of these correlations did not exceed 0.5 in either direction. The initial significant correlations disappeared after controlling for the available confounders, especially the provincial covariate. This large degree of heterogeneity between the provinces makes it difficult to assess for an effect of the family physician supply per 10000 population at a country level.

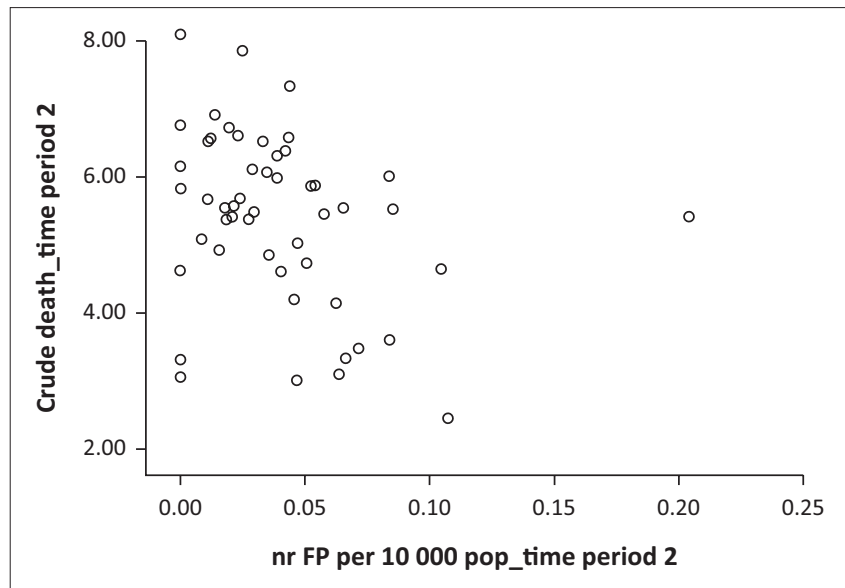

FIGURE 4: Scatter plot of significant correlation $(p<0.05)$ : supply of family physician (FPs) and inpatient crude death rate for time period 2 (2014/2015).

\section{Strengths and limitations}

Our study was limited by our definition of primary care physician supply, by excluding primary care doctors who were not registered as family physicians with the Health Professions Council of South Africa. A further limitation is the exclusion of private sector family physicians who may have an indirect effect on DHS performance, as they are seeing uninsured patients for out-of-pocket consultations. Some private sector family physicians may be contracted into public sector primary care facilities in the NHI pilot districts since 2013.

The study was also limited by the set of $\mathrm{DHB}$ variables that were determined by the $\mathrm{NDoH}$ and were not specifically intended to measure the impact of the family physician. The DHB data are based on routinely collected data which may lack the rigour required for research, although HST applies statistical methods to clean and improve data quality. Data quality issues of source data were described in the DHB. ${ }^{35}$ Furthermore, our analysis was limited by the availability of data for all indicators in both time periods, as an analysis over time is more sensitive to the effect of family physicians as opposed to a cross-sectional analysis.

\section{Implications or recommendations}

While this study from a broad macro-level district perspective did not demonstrate an impact of the family physicians on the DHS performance, other studies to be published elsewhere will present additional data from the facility and individual levels. These studies at a meso-level and a micro-level are more likely to demonstrate an impact as they evaluate the family physicians closer to their circle of control and influence. The correlation analysis should be repeated in 5 years, when the family physician supply is greater. It is also recommended that this correlation analysis includes a comparison with a broader definition of primary care doctor supply (all primary care doctors working in the DHS).

TABLE 4: Generalised linear model (regression analysis) to control for the effect of province on the correlation between changes in family physician supply per 10000 population and vaccine expenditure per population under 1 year.

\begin{tabular}{|c|c|c|c|c|c|c|c|}
\hline \multirow[b]{2}{*}{ Parameter } & \multirow[b]{2}{*}{ B } & \multirow[b]{2}{*}{ s.e. } & \multicolumn{2}{|c|}{$95 \%$ Wald confidence interval } & \multicolumn{3}{|c|}{ Hypothesis test } \\
\hline & & & Lower & Upper & Wald Chi-square & df & Sig. \\
\hline (Intercept) & -107.949 & 104.9363 & -313.620 & 97.722 & 1.058 & 1 & 0.304 \\
\hline FPppop_change & 376.198 & 2153.2942 & -3844.181 & 4596.577 & 0.031 & 1 & 0.861 \\
\hline$[$ Province $=E C]$ & 402.050 & 134.5360 & 138.365 & 665.736 & 8.931 & 1 & 0.003 \\
\hline [Province=FS] & 9.567 & 155.9614 & -296.111 & 315.246 & 0.004 & 1 & 0.951 \\
\hline [Province $=\mathrm{GP}]$ & 1611.691 & 149.7983 & 1318.092 & 1905.290 & 115.758 & 1 & 0.000 \\
\hline$[$ Province $=K Z N]$ & 424.724 & 123.3641 & 182.935 & 666.513 & 11.853 & 1 & 0.001 \\
\hline [Province $=\mathrm{LP}]$ & 1023.000 & 150.5760 & 727.876 & 1318.123 & 46.157 & 1 & 0.000 \\
\hline [Province=MP] & 155.624 & 170.7158 & -178.973 & 490.220 & 0.831 & 1 & 0.362 \\
\hline [Province $=\mathrm{NC}$ ] & -355.870 & 170.6256 & -690.290 & -21.450 & 4.350 & 1 & 0.037 \\
\hline [Province=NW] & 1210.934 & 160.8308 & 895.711 & 1526.156 & 56.689 & 1 & 0.000 \\
\hline [Province $=W C$ ] & $0^{\mathrm{a}}$ & & & & & & \\
\hline (Scale) & $57991.602^{\mathrm{b}}$ & 11716.0729 & 39029.809 & 86165.575 & & & \\
\hline
\end{tabular}

Dependent variable: Vacc exp per pop U1_difference Model: (Intercept), FPppop_change, Province.

, Set to zero because this parameter is redundant.

b. Maximum likelihood estimate.

Sig., significance level; df, degrees of freedom; s.e., standard error; B, regression; EC, Eastern Cape; FS, Free State; GP, Gauteng Province; KZN, KwaZulu-Natal; LP, Limpopo Province; MP, Mpumalanga; NC, Northern Cape; NW, North West; WC, Western Cape. 
TABLE 5: Generalised linear model (regression analysis) to control for the effect of province on the correlation between family physician supply per 10 000 population and inpatient crude death rate, for time period 2.

\begin{tabular}{|c|c|c|c|c|c|c|c|}
\hline \multirow[b]{2}{*}{ Parameter } & \multirow[b]{2}{*}{ B } & \multirow[b]{2}{*}{ s.e. } & \multicolumn{2}{|c|}{$95 \%$ Wald confidence interval } & \multicolumn{3}{|c|}{ Hypothesis test } \\
\hline & & & Lower & Upper & Wald Chi-square & df & Sig. \\
\hline (Intercept) & 3.250 & 0.3644 & 2.536 & 3.964 & 79.527 & 1 & 0.000 \\
\hline FP_time2 & -0.024 & 0.0251 & -0.073 & 0.025 & 0.932 & 1 & 0.334 \\
\hline$[$ Province $=\mathrm{EC}]$ & 3.129 & 0.4496 & 2.248 & 4.011 & 48.437 & 1 & 0.000 \\
\hline [Province $=\mathrm{FS}]$ & 2.660 & 0.4830 & 1.713 & 3.606 & 30.325 & 1 & 0.000 \\
\hline$[$ Province $=\mathrm{GP}]$ & 2.407 & 0.4788 & 1.469 & 3.346 & 25.275 & 1 & 0.000 \\
\hline [Province $=K Z N]$ & 2.338 & 0.4075 & 1.540 & 3.137 & 32.930 & 1 & 0.000 \\
\hline$[$ Province $=\mathrm{LP}]$ & 2.352 & 0.4860 & 1.400 & 3.305 & 23.422 & 1 & 0.000 \\
\hline$[$ Province=MP] & 2.611 & 0.5591 & 1.515 & 3.706 & 21.805 & 1 & 0.000 \\
\hline [Province $=\mathrm{NC}$ ] & 1.574 & 0.4971 & 0.600 & 2.549 & 10.027 & 1 & 0.002 \\
\hline$[$ Province $=\mathrm{NW}]$ & 3.550 & 0.5168 & 2.537 & 4.562 & 47.179 & 1 & 0.000 \\
\hline [Province $=W C]$ & $0^{\mathrm{a}}$ & & & & & & \\
\hline (Scale) & $0.625^{b}$ & 0.1226 & 0.426 & 0.918 & & & \\
\hline
\end{tabular}

Dependent variable: Crude death rate_time 2 Model: (Intercept), FP_time2, Province.

a, Set to zero because this parameter is redundant.

b, Maximum likelihood estimate.

Sig., significance level; df, degrees of freedom; s.e., standard error; B, regression; EC, Eastern Cape; FS, Free State; GP, Gauteng Province; KZN, KwaZulu-Natal; LP, Limpopo Province; MP, Mpumalanga; NC, Northern Cape; NW, North West; WC, Western Cape.

TABLE 6: Generalised linear model (regression analysis) to control for the effect of province on the correlation between changes in family physician supply per 10 000 population and percentage of TB cases with known HIV status.

\begin{tabular}{|c|c|c|c|c|c|c|c|}
\hline \multirow[b]{2}{*}{ Parameter } & \multirow[b]{2}{*}{ B } & \multirow[b]{2}{*}{ s.e. } & \multicolumn{2}{|c|}{$95 \%$ Wald confidence interval } & \multicolumn{3}{|c|}{ Hypothesis test } \\
\hline & & & Lower & Upper & Wald Chi-square & df & Sig. \\
\hline (Intercept) & 15.143 & 3.8935 & 7.512 & 22.774 & 15.127 & 1 & 0.000 \\
\hline [Province=EC] & 8.552 & 5.0515 & -1.349 & 18.453 & 2.866 & 1 & 0.090 \\
\hline [Province=FS] & 5.782 & 5.6366 & -5.265 & 16.830 & 1.052 & 1 & 0.305 \\
\hline [Province $=\mathrm{GP}]$ & 6.294 & 5.6398 & -4.760 & 17.348 & 1.246 & 1 & 0.264 \\
\hline [Province=KZN] & 7.198 & 4.6770 & -1.968 & 16.365 & 2.369 & 1 & 0.124 \\
\hline$[$ Province $=\mathrm{LP}]$ & 6.616 & 5.6577 & -4.473 & 17.705 & 1.367 & 1 & 0.242 \\
\hline$[$ Province=MP] & 5.978 & 6.4898 & -6.741 & 18.698 & 0.849 & 1 & 0.357 \\
\hline$[$ Province $=\mathrm{NC}]$ & 1.777 & 5.9560 & -9.896 & 13.451 & 0.089 & 1 & 0.765 \\
\hline [Province=NW] & 10.369 & 6.0384 & -1.466 & 22.204 & 2.949 & 1 & 0.086 \\
\hline$[$ Province $=W C]$ & $0^{\mathrm{a}}$ & & & & & & \\
\hline FPppop_change & -138.039 & 63.2795 & -262.065 & -14.014 & 4.759 & 1 & 0.029 \\
\hline (Scale) & $83.979^{b}$ & 16.4696 & 57.179 & 123.340 & & & \\
\hline
\end{tabular}

Dependent variable: TB known HIV status_difference Model: (Intercept), Province, FPppop_change.

, Set to zero because this parameter is redundant.

b, Maximum likelihood estimate.

Sig., significance level; df, degrees of freedom; s.e., standard error; B, regression; EC, Eastern Cape; FS, Free State; GP, Gauteng Province; KZN, KwaZulu-Natal; LP, Limpopo Province; MP, Mpumalanga; NC, Northern Cape; NW, North West; WC, Western Cape.

\section{Conclusion}

It is still too early to demonstrate the impact of an increase in supply of family physicians at the district level on key health system performance indicators, key clinical processes and key health outcomes. Studies which evaluate impact closer to the family physician's circle of control may be better positioned to demonstrate a measurable impact in the short term. A repeat correlation analysis is recommended in 5 years to allow for time (duration of effect) and training output (size of supply). Opportunities to deploy more family physicians within the DHS should be explored and supported.

\section{Acknowledgements}

The authors wish to acknowledge Health Systems Trust (in particular, Dr René English and Ms Naomi Massyn) and Dr Robin Dyers, Division of Community Health, Department of Interdisciplinary Health Sciences, Faculty of Medicine and Health Sciences, Stellenbosch University.
This study was conducted with the financial assistance of the European Union. The contents of this document are the sole responsibility of the authors and can under no circumstances be regarded as reflecting the position of the European Union. Additional funding was received from the Discovery Foundation (South Africa) and the Faculty of Medicine and Health Sciences, Stellenbosch University, South Africa.

\section{Competing interests}

The authors declare that they have no financial or personal relationship(s) that may have inappropriately influenced them in writing this article.

\section{Authors' contributions}

K.v.P. and R.J.M. conceptualised the study. K.v.P. prepared the database and conducted the data analysis with T.E. under the supervision of R.J.M. K.v.P. drafted the manuscript. All authors revised the manuscript and approved the final version. 


\section{References}

1. Management Sciences for Health. Health systems in action: An eHandbook for leaders and managers. Cambridge, MA: Management Sciences for Health [homepage on the Internet]. 2010 [cited 2016 Aug 30]. Available from: https:// www.msh.org/resources/health-systems-in-action-an-ehandbook-for-leadersand-managers

2. World Health Organization. The world health report 2008: Primary health care: Now more than ever. World Health Organization [homepage on the Internet] 2008 [cited 2016 Aug 30]. Available from: http://www.who.int/whr/2008/en/

3. Mash RJ, de Villiers MR, Moodley K, Nachega JB. Guiding the development of family medicine training in Africa through collaboration with the medical education partnership initiative. Acad Med. 2014;89(8 Suppl):S73-S77. https:// doi.org/10.1097/ACM.0000000000000328

4. Starfield B, Shi L, Macinko J. Contribution of primary care to health systems and health. Milbank Q. 2005;83(3):457-502.

5. Mash R, Ogunbanjo G, Naidoo S, Hellenberg D. The contribution of family physicians to district health services: A position paper for the National Department physicians to district health services: A position
of Health. S Afr Fam Pract 2014;57(3):54-61.

6. Starfield B, Shi L, Grover A, Macinko J. The effects of specialist supply on populations' health: Assessing the evidence. Health Aff (Millwood). 2005;Suppl Web:97-107.

7. Shi L, Starfield B, Kennedy B, Kawachi I. Income inequality, primary care, and health indicators. J Fam Pract 1999;48:275-284.

8. Macinko J, Starfield B, Shi L. Quantifying the health benefits of primary care physician supply in the United States. Int J Heal Serv. Baywood. 2007;37(1):111126. https://doi.org/10.2190/3431-G6T7-37M8-P224

9. McMurchy D. What are the critical attributes and benefits of a high-quality primary healthcare system [homepage on the Internet]. Canadian Health Services Research Foundation, 2009 [cited 2016 Aug 30]; p. 1-55. Available online a http://www.cfhi-fcass.ca/sf-docs/default-source/primary-healthcare/11498 PHC_McMurchy_ENG_FINAL.pdf

10. Vogel RL, Ackermann RJ. Is primary care physician supply correlated with health outcomes? Int J Heal Serv [serial online]. 1998;28(1):183-196 [cited 2016 Aug 30]. Available from: http://joh.sagepub.com/lookup/doi/10.2190/3B1X-EE5T-T7GR-KGUD

11. Gulliford MC. Availability of primary care doctors and population health in England: Is there an association? J Public Health Med. 2002;24(4):252-4. https:// England: Is there an association? J P
doi.org/10.1093/pubmed/24.4.252

12. Lee J, Park S, Choi K, Kwon SM. The association between the supply of primary care physicians and population health outcomes in Korea. Fam Med. 2010;42(9):628-635.

13. Gorey KM, Luginaah IN, Hamm C, Holowaty EJ, Balagurusamy M. The supply of physicians and care for breast cancer in Ontario and California, 1998 to 2006. Can J Rural Med. 2011;16(2):47-54.

14. Macinko J, Starfield B, Shi L. Quantifying the health benefits of primary care physician supply in the United States. Int J Health Serv [serial online]. 2007 [cited 2016 Aug 30];37(1):111-126. Available from: http://www.jhsph.edu/research/ centers-and-institutes/johns-hopkins-primary-care-policy-center/Publications PDFs/2007_IJHS_Macinko.pdf

15. Ssenyonga R, Seremba E. Family medicine' $s$ role in health care systems in SubSaharan Africa : Uganda as an example. Fam Med. 2007;39(9):623-626.

16. Mohamed KG, Hunskaar S, Abdelrahman SH, Malik EM. Scaling up family medicine training in Gezira, Sudan - A 2-year in-service master programme using modern information and communication technology: A survey study. Hum Resour Health 2014;12(1):3. https://doi.org/10.1186/1478-4491-12-3

17. De Villiers PJT. Family medicine as a new speciality in South Africa. S Afr Fam Pract. 2003;45(4):3.

18. De Maeseneer J. Scaling up family medicine and primary health care in Africa: Statement of the Primafamed network, Victoria Falls, Zimbabwe. J Prim Heal Care Fam Med. 2013;5(1):2009-12. https://doi.org/10.4102/phcfm.v5i1.507

19. Hellenberg D, Gibbs T. Developing family medicine in South africa: A new and doi.org/10.1080/01421590701827890
20. Mash B. Reflections on the development of family medicine in the Western Cape: A 15-year review. S Afr Fam Pract. 2011;53(6):557-562. https://doi.org/10.1080/ A 15-year review. S Afr Fam
20786204.2011.10874152

21. Ssenyonga R. Family medicine may be helpful in improving health care delivery in sub-Saharan Africa. Afr Health Sci [serial online]. 2007 [cited 2016 Aug 30];7(2):120-121. Available from: https://www.ncbi.nlm.nih.gov/pmc/ articles/PMC1925272/

22. Mash B. Family medicine is coming of age in sub-Saharan Africa. South African Fam Pract. 2008;50(6):50-1. https://doi.org/10.1080/20786204.2008. 10873789

23. Moosa S, Downing R, Mash B, Reid S, Pentz S, Essuman A. Understanding of family medicine in Africa: A qualitative study of leaders' views. Br J Gen Pract. 2013;63(608):e209-e216. https://doi.org/10.3399/bjgp13X664261

24. Moosa S, Downing R, Essuman A, Pentz S, Reid S, Mash R. African leaders' views on critical human resource issues for the implementation of family medicine in Africa. Hum Resour Health. 2014;12:2. https://doi.org/ 10.1186/1478-4491-12-2

25. Swanepoel M, Mash B, Naledi T. Assessment of the impact of family physicians in the district health system of the Western Cape, South Africa. Afr J Prim Heal Care Fam Med [serial online]. 2014;6(1):1-8 [cited 2016 Aug 30] Available from: https://www.ncbi.nlm.nih.gov/pmc/articles/PMC4565036/

26. Mash R, Downing R, Moosa S, De Maeseneer J. Exploring the key principles of family medicine in sub-Saharan Africa: International Delphi consensus process. S Afr Fam Pract. 2008;50(3):60-65. https://doi.org/10.1080/20786204.2008.1 0873720

27. National Health Insurance in South Africa. Policy (white) Paper. Government Notice No. 1230, Government Gazette No. 39506. Pretoria, South Africa: National Department of Health; 11 December 2015.

28. National Department of Health. Handbook for District Clinical Specialist Teams. Pretoria, South Africa: National Department of Health; 2014.

29. National Department of Health. Milestones in the implementation of the National Health Insurance [homepage on the Internet]. 2015 [cited 2016 Aug 30]; p. 1. Available from: http://www.health.gov.za/index.php/gf-tb-program/296-milestonesAvailable from: http://www.health.gov.za/index.php/gf-tb-pr
in-the-implementation-of-the-national-health-insurance

30. National Department of Health. Human resources for health South Africa: HRH strategy for the Health Sector: 2012/13-2016/17. Pretoria, South Africa; 2011.

31. Division of Family Medicine and Primary Care (Stellenbosch University). Strengthening primary health care through primary care doctors and family physicians (EuropeAid-funded project) [homepage on the Internet]. 2016 [cited 2016 Aug 30]. Available from: http://www.sun.ac.za/fammed

32. Dyers RE, Mash R, Naledi T. How far does family physician supply correlate with district health system performance? Afr J Prim Heal Care Fam Med. 2015;7(1):19. https://doi.org/10.4102/phcfm.v7i1.796

33. STROBE Initiative Group. STROBE Statement - Checklist of items that should be included in reports of cohort studies [homepage on the Internet]. 2007 [cited 2016 Aug 30]. Available from: http://www.strobe-statement.org/index.php?id=availablechecklists

34. Districts of South Africa. Wikipedia, the free encyclopedia [homepage on the Internet]. 2016 [cited 2016 Aug 30]. Available from: https://en.wikipedia.org/ wiki/Districts_of_South_Africa

35. Massyn N, Peer N, Padarath A, Barron P, Day CE. District Health Barometer 2014/15. Durban, South Africa: Health Systems Trust; 2015.

36. Day C, Barron P, Massyn N, Padarath A, English R. District Health Barometer 2010/11. Durban, South Africa: Health Systems Trust; 2012.

37. IBM Corp. IBM SPSS Statistics for Windows, Version 23.0 [homepage on the Internet]. Armonk, NY: IBM Corp.; 2015. Available from: http://www-01.ibm.com/ support/docview.wss?uid=swg24038592

38. Mukaka MM. Statistics corner: A guide to appropriate use of correlation coefficient in medical research. Malawi Med J. 2012;24(3):69-71.

39. Mash R, Almeida M, Wong WCW, Kumar R, von Pressentin KB. The roles and training of primary care doctors: China, India, Brazil and South Africa. Hum Resour Health. 2015;13(1). https://doi.org/10.1186/s12960-015-0090-7 